\title{
Rutas Turísticas en la CiUdAd de Quito CON PERSPECTIVA CULTURAL PARA PERSONAS DISCAPACITADAS
}

\author{
TOURIST ROUTES IN THE CITY OF QUITO WITH CULTURAL PERSPECTIVE FOR PEOPLE \\ WITH DISABILITIES
}

\author{
Mg. Ismari Gómez Díaz \\ Universidad Israel \\ igomez@uisrael.edu.ec \\ Fecha de recepción: 2/02/2015 \\ Fecha de aceptación: 2 /03/2015
}

\begin{abstract}
Resumen
La ciudad de Quito como destino turístico ofrece un profundo patrimonio cultural tangible e intangible que necesita ser incorporado con plenitud al universo del turista con discapacidad. En este artículo analizamos una serie de barreras comunicacionales que impiden que todo el legado cultural de la ciudad sea valorado, interpretado y asumido por una población turística tan vital como lo constituyen los turistas de este importante segmento.

Las diferentes carreras que se ocupan de formar profesionales del turismo juegan un rol definitorio en la problemática antes expuesta y su identificación con el universo cultural de la ciudad de Quito. Se aprecia como problemática del presente trabajo incluir al potencial turístico de la ciudad una ruta con perfil cultural para personas con discapacidad. De la anterior problemática se deriva como objetivo general analizar las diferentes barreras que dificultan el acceso de los turistas con discapacidad a una ruta con perfil cultural en la ciudad de Quito.
\end{abstract}


La observación, como método de investigación, nos permite constatar lo antes apuntado. De igual modo, el análisis de documentos que rigen la política del turismo en el país y los que se ocupan de la organización académica de la enseñanza de los profesionales de esta disciplina nos aportan datos que validan nuestra problemática.

Palabras clave: Rutas turísticas, patrimonio, discapacidad, accesibilidad, barreras

\section{Abstract}

The city of Quito as a tourist destination offers a deep cultural tangible and intangible heritage which needs to be fully incorporated into the universe of tourists with disabilities. In this article we will analyze the communicational barriers that are stopping that the whole cultural legacy of the city could be valued, interpreted and assumed for such a vital touristic group as it is the one formed by this segment. The different careers dealing with any form of tourism professionals play a defining role in the previously exposed problems and its identification with the cultural universe of the city of Quito.

It's contemplated in this work to include to the touristic potential of the city a route with the cultural profile for people with disabilities. The previous problem is derived as general objective analyze the different barriers that hinder the access of tourists with disabilities to a route with the city of Quito cultural profile.

Observation as a research method allows us seeing the problem targeted before. In the same way, analysis of documents that dictate the politics of tourism in the country, and those dealing with the academic organization of education of the professionals of this discipline provide us data that validate our situation.

Keywords: Tourist routes, heritage, disability, accessibility, barriers 


\section{Introducción}

La ciudad de Quito ofrece una amplia gama de atractivos turísticos que se pueden constatar desde una diversidad cultural e histórica. Calles y plazas que evocan una tradición centenaria, diversidad arquitectónica que señala la continuidad del desarrollo de una ciudad que no deja de sorprender por su capacidad de renovarse a sí misma.

Carita de Dios, Mitad del Mundo, El Alma del Mundo o Luz de América son algunos de los nombres con los que se ha bautizado a la ciudad desde el imaginario popular y que apuntan a un profundo sentido de pertenencia e identificación. Fundada el 6 de diciembre de 1534, es la primera ciudad declarada, junto a Cracovia en Polonia, como Patrimonio Cultural de la Humanidad por la Unesco, el 18 de septiembre de 1978. Quito posee el centro histórico más grande, menos alterado y mejor preservado de América.

Toda la ciudad y el Distrito Metropolitano se encuentran entre los estilos Contemporáneo y Colonial, que se están reconstruyendo constantemente día a día. La estructura moderna se mezcla con la colonial, donde los residentes nacionales y los visitantes extranjeros encuentran siempre un lugar para estancias o visitas prolongadas. Además, la ciudad está rodeada por los volcanes Pichincha, Antisana, Cotopaxi, y Cayambe que conforman el contorno andino.

Quito está colmada de significados que la identifican y definen, ocupa laderas o baja a los valles, serpentea a través de callejones y se abre en amplias avenidas; zigzaguea, sorteando colinas y quebradas. Por esta belleza física, sus tradiciones, rincones de misticismo y leyendas vigentes es considerada "Relicario del Arte en América".

En consonancia con sus atractivos naturales y sus encantos arquitectónicos, la ciudad como destino turístico ha sido ampliamente reconocida a nivel internacional. El manejo integral de la ciudad se ha visto reflejado en los seis premios internacionales que ha obtenido. En el año 2013, Quito fue reconocida como la "mejor ciudad destino del mundo" para visitarla. Así lo expuso la National Geographic Magazine - New York.

La situación actual de la ciudad de Quito y sus atractivos turísticos de corte cultural en relación con los discapacitados, nos muestra la no existencia de rutas que favorezcan totalmente la inclusión de los mismos. Por ello nos proponemos como objetivo central de nuestra investigación analizar las diferentes barreras que dificultan el acceso de los turistas con discapacidad a una ruta con perfil cultural en la ciudad de Quito. 


\section{Desarrollo}

En 2013, Ecuador atrajo a 1’360.000 turistas extranjeros. El turismo, que hasta ahora era la cuarta fuente de ingresos del país, pasó a ocupar el tercer lugar con ingresos cercanos a los 1500 millones de dólares y una creciente generación de empleo, siendo ya un sector considerado de enorme potencial para el futuro del país sudamericano.

La conjunción del patrimonio cultural tangible e intangible que se verifica en la ciudad de Quito presenta una amplia representatividad en su reconocimiento internacional como destino turístico. Todo un entramado de leyendas, tradiciones, tipología humana, manifestaciones de la cultura popular tradicional, conforma una realidad social e histórica que además de ser identificada por el visitante, es asumida por los habitantes como práctica común de vida e identidad.

El sentido de pertenencia del quiteño es una de las grandes ganancias de la historia de la ciudad. Tal sentido se articula con la amplitud y profundidad del significado cultural que la ciudad enarbola como distintivo. El patrimonio está constituido por recursos que, en principio, se heredan y de los que se vive. Ello quiere decir que, a lo largo de esa vida se modifican necesariamente: en algunos apartados se incrementan sin más; en otros, evolucionan hacia nuevas formas, mientras algunos aspectos de ese patrimonio desaparecen (De Lorenzo, 2003: p. 14).

La diversidad de conceptualizaciones sobre patrimonio cultural tangible e intangible ha sido debidamente documentada por diversas disciplinas y ciencias del ámbito de los estudios sociales y culturales.

En los estudios turísticos, tales conceptos son asumidos desde la propia concepción de rutas y destinos. En tal sentido se define patrimonio tangible como inmuebles, lugares, sitios, edificaciones, obras de ingeniería, centros industriales, conjuntos arquitectónicos, zonas típicas y monumentos de interés o valor relevante desde el punto de vista arquitectónico, arqueológico, histórico, artístico o científico, reconocidos y registrados como tales.

Estos bienes culturales inmuebles son obras o producciones humanas que no pueden ser trasladadas de un lugar a otro, ya sea porque son estructuras (por ejemplo, un edificio), o porque están en inseparable relación con el terreno (por ejemplo, un sitio arqueológico).

Los valores patrimoniales no necesariamente son reconocidos de igual manera por todos los miembros de una comunidad. Distintos grupos sociales y culturales pueden reconocer en un mismo atributo diversos valores, incluso contradictorios entre sí. De ahí su grado de subjetividad.

Forman parte de esas valoraciones referentes colectivos relacionados con la religión, la educación, o la conciencia individual, y dependen de los mecanismos que cada sociedad tiene para su transmisión: la familia, la escuela, o los medios de comunicación. 
Al mismo tiempo, algunos de estos valores, en especial aquellos relacionados con los grupos culturales de mayor poder, pueden estar formalizados por las leyes y normas oficiales, transformándolos en discurso institucionalizado y colectivo, el cual no necesariamente se corresponde en la práctica con la multiplicidad de valores sociales relacionados con el bien cultural (Caraballo, 2011: p.27).

Cualquier elemento cultural de nuestro entorno es susceptible de ser patrimonializado: construcciones, sonidos y silencios, acontecimientos o personajes históricos, mitos o leyendas, paisajes, olores y sabores (Patrimonio Cultural y Derechos Colectivos, 2012).

El patrimonio intangible está constituido, entre otros elementos, por la poesía, los ritos, los modos de vida, la medicina tradicional, la religiosidad popular y las tecnologías tradicionales de nuestra tierra. Integran la cultura popular las diferentes lenguas, los modismos regionales y locales, la música y los instrumentos musicales tradicionales, las danzas religiosas y los bailes festivos, los trajes que identifican a cada región de Ecuador, la cocina, los mitos y leyendas; las adivinanzas y canciones de cuna; los cantos de amor y villancicos; los dichos, juegos infantiles y creencias mágicas.

En el caso de las rutas turísticas que persiguen un fin cultural en la ciudad de Quito, patrimonio cultural tangible e intangible conforman una unidad indisoluble.

Un punto de encuentro donde el turista adquiere una ganancia humana de connotaciones espirituales profundas y perdurables. En virtud de lo antes expuesto, valoramos la pertinencia de que este enriquecimiento cultural alcance a la totalidad de los turistas que visitan la ciudad, independientemente de sus potencialidades o niveles culturales, capacidades o discapacidades funcionales.

Los derechos de las personas discapacitadas requieren de un tratamiento más amplio y diferente al establecido en el contexto de la rehabilitación y los servicios sociales y deben incluir todos los Derechos Humanos (Colectivo de Autores, 2004: p.42).

El impacto de la discapacidad se podría reducir mejorando la calidad de vida de la población con discapacidad, con todos los beneficios que esto conlleva para el conjunto de los habitantes del país y el propio desarrollo nacional (Ministerio de Educación, 2005: p.27).

La casi totalidad de los destinos turísticos a escala mundial, independientemente de sus fines y proyecciones, ya contemplan entre sus articulaciones y viabilidades una orientación objetiva y funcional hacia los turistas con discapacidades de todos los tipos. El turismo para personas con discapacidad es un segmento de mercado que cada vez cobra mayor importancia dentro de la industria turística internacional. Esto se debería básicamente a la suma de cuatro factores:

- Un aumento del tamaño del mercado, ya que a medida que se incrementa la esperanza de vida, crece el número de personas con alguna discapacidad; 
- Mejora en los ingresos que percibe este grupo, como consecuencia de la existencia de nuevas leyes de carácter social;

- Las mejoras tecnológicas que permiten mayor información y desplazamiento, y por ende posibilitan la realización de viajes;

- Finalmente un incremento en las facilidades y servicios para personas con discapacidad, tanto por una toma de conciencia de los requerimientos existentes como en respuesta a la creciente demanda de los mismos. (De Lorenzo García, 2003: p. 27).

Ante esta realidad, los grandes destinos y polos turísticos desde décadas anteriores ya han venido conformando una serie de políticas institucionales de readaptación de sus modelos de servicios y acondicionamiento técnico de sus instalaciones.

De modo que hablar de un turismo accesible es ya una constante para los profesionales del mercado turístico. De igual manera, disminuir las barreras que impiden mayores niveles de accesibilidad.

El concepto de accesibilidad comprende y vincula a muchos ámbitos espaciales y de comunicación, afecta a muchas personas de distinto tipo (con o sin discapacidades, jóvenes o mayores), abarca múltiples actividades (la comunicación, el transporte, el ocio, el turismo...) y, en consecuencia, tiene múltiples perspectivas (la de cada tipo de discapacidad, la de los mayores, la de los que llevan niños, la de los que diseñan los objetos, protocolos o espacios, etc.).

En definitiva, es difícil no dar una visión reduccionista de la accesibilidad; máximo cuando existe bastante precariedad de datos, estadísticas o estudios fiables sobre las diversas materias a incluir en el análisis (Colectivo de autores, 2003: p.26).

El término «accesibilidad» proviene de «acceso», acción de llegar y acercarse, o bien entrada o paso. Aplicado al uso del espacio o de objetos y tecnologías, y especialmente con relación a ciertos colectivos de población con dificultades funcionales, la palabra adquiere un matiz menos neutro, más expresivo de los beneficios que se derivan de la interacción con el entorno o con otras personas (Colectivo de autores, 2003: p.26).

La literatura especializada en el tema de barreras que dificultan la accesibilidad reconoce tres tipos fundamentales: barreras físicas, barreras comunicacionales y las llamadas barreras sociales.

Por su significación para la debida incorporación del turista con discapacidad al disfrute pleno de una ruta turística en la ciudad de Quito, con perspectiva cultural, nos centraremos en las barreras comunicacionales, como aspecto que lastra la debida asimilación de todo el potencial cultural, tangible o intangible de la ciudad de Quito al universo vivencial del turista con discapacidad. 
En las barreras comunicacionales se reconoce una serie de elementos que por su significación vale la pena resaltar.

- Falta de guías y profesionales que puedan expresarse en lenguaje de señas.

- Falta de material e indicaciones en Braille para su lectura por parte de personas no videntes.

- Falta de cartelería informativa adecuada.

- Falta de servicios de telefonía adaptados.

- Falta de medios recreativos de comunicación, que sean accesibles.

- Falta de capacitación de los profesionales turísticos, para una adecuada atención a personas con dificultades en la expresión, o en su percepción visual o auditiva.

Cada uno de estos elementos es una realidad en la actual situación de las rutas turísticas de la ciudad de Quito que persiguen un fin cultural. De esta realidad se desprende que buena parte del potencial cultural tangible o intangible que la ciudad de Quito ofrece como destino turístico, no está siendo debidamente incorporado al consumo de un mercado como es el de los turistas con discapacidad. Mercado que, si bien posee necesidades propias, también es cierto que es dinámico y vital.

Al tomarse conciencia de los factores sociales que integran el fenómeno de la discapacidad, las soluciones no se elaboran apuntarse individualmente a la persona afectada, sino más bien que se encuentran dirigidas hacia la sociedad, o teniendo muy presente el contexto social en el cual la persona desarrolla su vida. A partir de dichas premisas, el modelo social redefine la rehabilitación o normalización, estableciendo que éstas deben tener como objeto el cambio de la sociedad, y no de las personas. Desde esta perspectiva, ciertas herramientas, como el diseño para todos y la accesibilidad universal cobran una importancia fundamental como medio de prevención de situaciones de discapacidad (Palacios, 2008: p.124).

La necesidad de reconocer la importancia de un turismo de amplia accesibilidad debe constituir uno de los núcleos articuladores en el momento de concebir las mallas curriculares de las diferentes carreras de turismo del país.

Destacamos la pertinencia de incluir asignaturas que potencien lo comunicacional, lo participativo, lo interactivo y lo recreativo, hacia el universo del turista con discapacidad. Desde la propia formación del profesional del turismo se puede incidir en una problemática que en la actualidad impide niveles de plenitud y satisfacción del turista con discapacidad con todo el universo cultural tangible e intangible que la ciudad de Quito ofrece como destino turístico.

\section{Conclusiones}

La ciudad de Quito, como destino turístico, ofrece un amplio patrimonio cultural tangible e intangible que puede ser incorporado de forma óptima al universo del turista con discapacidad. 
Las diferentes instituciones que conforman el polo turístico de Quito deben valorar los niveles de accesibilidad que presenta para el turista con discapacidad que se interesa por un turismo de corte cultural.

Las carreras de turismo del país precisan en sus mallas curriculares asignaturas que posibiliten la formación de profesionales capaces de interactuar con el universo vivencial y afectivo del turista con discapacidad. 


\section{Bibliografía}

Ballart Hernández, J. (2007). Manual de Museos. Barcelona: Editorial Síntesis

Cabra de Luna, M. (2003). Personas con Discapacidad y Derecho: Cuestiones de Actualidad y Ejes para una Renovación Jurídica en Las Múltiples Dimensiones de la Discapacidad. Madrid: Libre Editorial.

Colectivo de autores (2003). Libro Blanco de la Accesibilidad. Barcelona: Ediciones UPC/ Mutua Universal

De Lorenzo García, R. (2003). El futuro de las personas con discapacidad en el mundo. Desarrollo humano y Discapacidad, Fundación ONCE, Madrid: Ediciones del Umbral.

Ministerio de Educación. (2004). In- clusión social, discapacidad y políticas públicas. Chile: Unicef.

Palacios, A. (2008). El modelo social de discapacidad: orígenes, caracterización y plasmación en la Convención Internacional sobre los Derechos de las Personas con Discapacidad. Madrid: Ediciones Cinca.

Perichi Araballo, C. (2011). "Patrimonio Cultural, un enfoque diverso y comprometido, Revista Andaluza De Antropología". Número 2: Patrimonio Cultural y Derechos colectivos, México: Oficina de las Naciones Unidas para la Educación, La Ciencia y la Cultura (Unesco). 
